\title{
The Athabasca University eduSource Project: Building an accessible learning object repository
}

\author{
Martha Cleveland-Innes, Rory McGreal, Terry Anderson, Norm \\ Friesen, Mohamed Ally, Tony Tin, Rodger Graham, Susan Moisey, \\ Anita Petrinjak and Steve Schafer \\ Athabasca University, Canada

\begin{abstract}
Athabasca University - Canada's Open University (AU) made the commitment to put all of its courses online as part of its Strategic University Plan. In pursuit of this goal, AU participated in the eduSource project, a panCanadian effort to build the infrastructure for an interoperable network of learning object repositories. AU acted as a leader in the eduSource work package, responsible for the metadata and standards for learning objects. In addition, the team of professionals, academics, librarians and other researchers worked to create an accessible repository of learning objects across university departments and subjects. Most critically, the team worked beyond the development of a learning object repository and considered the adaptation of content and related applications, pedagogical approaches and the use of learning objects by instructional designers, faculty and the learners themselves. This paper describes one institution's approach to learning object repository development, from a technical and pedagogical perspective, along with some of the lessons learned during the process.
\end{abstract}

\section{Introduction}

The opportunity to consider the application and use of learning objects came on the heels of significant efforts to identify, tag and meta-tag information items that could be applied in learning settings. Many possibilities for human growth and development through learning objects exist; eduSource was created to build a repository of objects that was highly efficient and accessible to those wishing to retrieve and use learning objects in formal education settings. The eduSource group at Athabasca University - Canada's Open University (AU), came together to create such a virtual space in support of the University's mission: the removal of barriers that restrict access to, and success in, university level studies and to increasing equality of educational opportunity for adult learners worldwide. Most critically, the AU team worked beyond the development of a learning 
object repository and considered the adaptation of content and related applications, pedagogical approaches and the use of learning objects by instructional designers, faculty and the learners themselves.

AU has been a partner in the pan-Canadian eduSource project, sponsored by CANARIE, Canada's advanced Internet development organization (CANARIE, 2004). CANARIE has contributed a total of CDN\$4.5 million (Canadian dollars) to the eduSource project. AU, along with its five eduSource Canada partners, built the components and best practice guidelines to develop the infrastructure for a pan-Canadian testbed of linked and interoperable learning object repositories, based on national and international standards (McGreal et al., 2004). AU received CDN\$688,500 from CANARIE, Canada's broadband network organisation, and has spent more than $\$ 1.6$ million on the project implementation. The partners collectively have contributed more than $\mathrm{CDN} \$ 5.5$ million. Additional funding of CDN\$150 000, specifically for learning object adaptations was provided by Canada's Schoolnet http:/ / www.schoolnet.ca/

$\mathrm{AU}$, as a partner in the eduSource initiative, was responsible for promoting the project objectives. These included providing Canadian leadership in learning object repository development through the creation of a testbed and examining issues of interoperability, including linking different repositories. Specifically, AU was charged with the leadership of the metadata standards implementation using the CanCore Metadata implementation guide and the development of a working prototype of a learning object repository for a university called $A D L i b$.

The CanCore Metadata implementation guide is being used by AU implementers and many others internationally in the creation of interoperable repositories. However, this project looked to the use of learning objects beyond storage in repositories. AU, as part of its commitment to put all of its courses online, produced a Digital Reading Room (DRR) and a prototype for an advanced learning object repository conforming to international standards for interoperability. This work was supported by research into the development of learning objects and their implementation in different courses. The work of multiple teams addressing all stages of repository development and implementation is reported below.

\section{Repository creation research and development}

\section{Ensuring ease of discovery of learning objects}

The CanCore version 2.0 metadata guidelines [http://www.cancore.ca/] are complete, with additional implementation guidelines for all of the elements in the IEEE Learning Object Metadata (IEEE LOM) standard 
(IEEE, 2003). These guidelines are being used by partners in the eduSource project, and by implementers around the world (Friesen, 2004). CanCore is an instantiation of the IEEE LOM standard. As such, it occupies the middle ground between this standard and the work needed to create an interoperable body of metadata records. CanCore is not intended to compete with or be used in place of the LOM. More recent adopters include the US based MERLOT repository [http:/ / www.merlot.org/]. The CanCore developers are international leaders in the development of a set of data elements for the next "generation" of the IEEE LOM. This is taking place in the context of the ISO sub-committee on Information Technology for Learning, Information and Training (ISO, n.d.).

The metadata supported by CanCore in eduSource has been specifically developed and adapted for the description of rich, bandwidth intensive multimedia resources. By contributing to the development of the open, technical standards for e-learning, the metadata work-package has helped to address the structural barriers presented by ad hoc and proprietary solutions. These standards allow for greater reuse and portability of resources, systems and content of many kinds across applications and operating systems.

A secondary objective of eduSource is to share the benefits of using CanCore with other groups creating repositories. A major obstacle in the dissemination of CanCore has been that of communicating the complexities of the LOM standard clearly, and explaining the precise nature of CanCore's contribution to its implementation. The AU implementers found that the IEEE LOM and related e-learning standards are too complex for ready and inexpensive implementation and use in publicly funded contexts. Close collaboration between those adapting and profiling the learning objects and those implementing standards was found to be essential. CanCore represents the state of art of e-learning resource metadata in Canada and it is widely recognised internationally. By providing extensive best practice guidelines and examples for the implementation of all of the elements in the LOM, CanCore makes an important contribution to this critically important field.

Both groups responsible for the future development of the LOM (IMS and the IEEE LOM subcommittee on metadata) acknowledge the widespread investment in this standard, and pledge to contribute to its stability and to protect these investments. Neither changes in this metadata standard nor its deprecation through other metadata standardisation work will likely occur for the next few years. This guarantees that the foundational interpretation and guidance work of CanCore will also be of direct value to implementers for the foreseeable future. At the same time, however, the conditions and conventions of its implementation are changing, and will 
continue to change. Work must be continuous to maintain and employ the highest standard possible.

As implementation moves from testbed and beta level technologies to production level facilities, the types of supports that are required for metadata interoperability are certain to change as well. The use of IEEE LOM elements seems to be converging on a subset of elements that are not dissimilar to those identified in the Dublin Core Metadata Element set (DCMI, n.d.). Also, as software develops further, the provision of common components and component libraries may be of increasing value.

Version 2.0 of CanCore is available in French and English in print, PDF and dynamic, searchable web based forms (Friesen et al., 2004). Using the latter format, it is possible to call up CanCore recommendations for the SCORM, SingCore and other metadata subsets (Advanced Distributed Learning, 2003; E-Learning Competency Centre, 2004).

\section{Populating the repository}

Repository construction involved the testing of prototypes of varieties of learning objects. This involved populating the repository with different learning content types to test their function, interoperability, resource discoverability and robustness. The learning objects uploaded have been metatagged according to CanCore standards using the ADLib database upload function. They vary in size, granularity, media type and pedagogical approach. The learning objects are based on existing AU course materials and besides text, include XML (Extensible Markup Language) text files, images, Flash files, as well as audio and video clips and other multimedia applications. The learning objects have also been semantically tagged.

Populating the repository involved work modeling materials and processes to create learning objects that provide high quality components for online courses. This work included creating templates for learning object production based on an AU learning object XML schema, which was also developed by the AU team. These templates are derived from modeling and prototyping the conversion of existing educational material (different formats) into modularised learning objects (based on the AU learning object XML schema and XHTML). These learning objects have been tested and the system is functioning.

On completion of the eduSource project, more than 200 learning objects of varying types, sizes, and pedagogical approaches were implemented. In the process, course developers worked through and documented a number of issues including file naming conventions, recommendations for titling 
objects, and recommendations for Cancore elements, as well as testing the upload and search capabilities of the ADLib repository. The semantic tagging has rendered the learning objects more versatile, increasing their range for reuse and discoverability. Researchers, semantically tagging legacy content, created an XML schema that was used to tag content and then retrieve it and display in various formats using XSLT style sheets. The schema builds on the work of Bartz (2002), but pays more attention to newly emerging IMS educational standards. The schema consisted of 15 elements (all but identification being optional). The elements were developed inductively from examination of existing content and include tags such as 'learning objectives' assessments', 'pre-requisites' and 'content.' The AU team also created a Java editor based on the schema to facilitate tagging of content (Petrinjak \& Graham, 2004).

The largest challenge faced by the course developers was converting the existing course material from Quicksilver/Interleaf (the format in which most of the legacy content existed) to clean XML text (Broadvision, 2003). Files output from Quicksilver require a great deal of editing before they can be useful as XML based learning objects. Very little of this process can be automated. It takes effort and time to convert legacy material into learning objects ready for use and reuse in an online environment due to unclean code exported by the currently used proprietary tools. While there are external companies who offer translation services, the cost is high and the output does not appear to match AU needs. It is more effective and more economical to hire and train personnel to do the translation in house. AU course developers found that it requires a significant amount of human intervention and editing, depending on how complex and "dirty" the original text is. Semantic tagging of learning objects also requires human editing and usage of the tagging tool.

AU course developers stress the importance of using open standards for educational content, such as XML and XHTML. They also emphasised the value of separating the content from the display formatting. In this way, intervention on the content can be done independently.

\section{Creating and researching open access to learning objects}

\section{Ensuring ease of learning objects access through library support}

In any university, student support is enhanced with a robust course reserve service. This service facilitates access by students to library materials that have been selected by faculty and are specific to a particular course. Often access to these materials is required to complete the course. For an online university like $\mathrm{AU}$, these reserves must (as much as possible) be made available to students online with the same quality of service or better than 
that provided to students on campus in the university library. The expansion of accessibility to the Internet and particularly, the growth of the world wide web have opened up a broad range of possibilities for facilitating student access to course relevant library materials and to other materials that are becoming available and accessible online. These "ereserves" are available at any time of the day or night from anywhere. Students accessing materials online no longer have to wait in line, fill out forms, and deal with disappointment when the materials are not available.

Early indications from students are that learning object repositories do not provide the correct interface to engage learners. However, independent lifelong learning is one goal attached to learning object development. Learner access to choose and use learning objects then must be integrated into learning object creation and storage/retrieval. This research team used the Digital Reading Room (DRR) at AU as an effective interface.

The DRR began as an online repository of "reserve" articles and other course materials that were tagged for use in specific courses [http://library.athabascau.ca/drr/]. Development of the DRR depended on meeting the administrative and pedagogical needs of the AU users. Administrative users required a stable but flexible system, capable of incorporating different types of learning object resources into the DRR. Reliable authentication was considered essential, but ease of use, including a user friendly method of data entry, modification, and retrieval was considered to be paramount by faculty. Student users also required stability and reliable access to multiple types of learning resources at any time of the day or night, along with the capacity to connect, view and/or manipulate search results.

The DRR is a basic e-course reserve system that is based on an SQL database, running on a Linux server. It generated interest among groups on campus in the development of a digital objects repository as a learning object repository to encourage sharing and reuse of learning objects for AU curriculum development. By August 2005, there were more than 14,000 learning objects available for more than 280 courses on the DRR.

\section{From reading room to course repository}

As part of their project work, AU eduSource researchers recognised that end user testing and input into the development and implementation was essential. Compatibility linkages had to be established between IEEE LOM (for access to a wide range of resources in a repository environment) and MARC (for access to a wide range of resources historically organised and accessed on the basis of the standards of the international library community). In addition, there continues to be a need for more user 
training and skill development in the searching and researching processes. Information literacy is essential.

AU has built a learning object repository known as ADLib (Athabasca University Digital Library) [http://adlib.athabascau.ca/]. ADLib is a metadata and learning object repository providing access to searchable and reusable digital resources for technology supported learning. ADLib uses the more powerful PostgreSQL as the data base management system (DBMS) and Cocoon XML publishing framework to format the learning objects. The ADLib architecture forms an extended base and platform for more electronic course reserve systems. ADLib is presently based on a PostGres database with plans to port it to Oracle $8 \mathrm{i}$.

ADLib was developed as a metadata compatible learning object repository that goes beyond a basic electronic course reserve system. Electronic course materials inputted into ADLib are stored and displayed as learning objects. This approach requires no external reference and can ensure the high quality of the learning objects. Second, it can encourage sharing and reuse of learning objects for electronic course reserve development. A user can search for existing learning objects in ADLib and reuse them in different courses. This reuse feature allows faculty to assemble learning objects from the repository to build customised electronic course materials tailored to meet their curriculum needs. Based on the work of the IMS group, a set of 13 fields has been determined to tag for each ADLib learning object that include the usual identifiers, such as author, title, URL, medium, copyright restrictions, languages, context, and program suitability. AU users, however, require only a minimum set of attributes (five fields) to be entered into tags for each learning object. AdLib is equipped with many new features, such XML record display, global unique identifier, discipline browsing, Cancore metadata profiles, learning object upload, simple and advanced searching, and FAQ Agent. It is interoperable with other Canadian learning object repositories through the use of a federated search engine:

http:/ / www.licef.teluq.uquebec.ca/demoprod/edusource2/eng/search.htm

In addition, it allows repositories around the world to harvest ADLib data through the implementation of the Open Archives Initiative Protocol for Metadata Harvesting (OAI-PMH) service.

\section{From input to output - drawing on the repository for course design}

IMS Learning Design (IMS LD) (IMS, 2003) is the successor to the Educational Modeling Language (Learning Networks of Educational Technology Expertise Centre of the Open University of the Netherlands, n.d.). It is perhaps the most complicated and full featured of the educational specifications supported by the IMS. It provides a formal 
specification for the expression of a course in terms that not only define the content, but also the actors (student, learner, staff, etc.) their activities, the resources and context in which they work and the means by which their learning is assessed. AU developers were able to use generic XML editors to markup examples of AU curriculum to create valid IMS LD files, thus proving the capacity of the language to describe the content.

However, there are as yet no tools to play these files in run time, so the success was somewhat limited. The developers realised that work needed to be expended on developing easy to use tools for both the creation and the run time display of content formatted in IMS LD. They therefore began work in conjunction with colleagues at the Téléuniversité du Québec and the University of Waterloo on a number of products, including a tree based LMS editor; a Java binding for the XML description of IMS LD, which was deemed critical for the creation of additional tools; and a tool that parses the output from a revised graphic design tool to create valid IMS LD.

This work was hindered because of the lack of existing tools to create, verify and run IMS LD files. This forced AU course developers to work with legacy tools to allow valid IMS LD to be produced. The complexity of the design and the persistent skepticism among the community has led some AU researchers to believe that the design may be too difficult for implementation at this time (Athabasca University Learning Design Group, 2004).

\section{Course construction based upon learning objects}

The creation, cataloging and effective retrieval of learning objects is merely a developmental exercise unless the tools and techniques lead to more effective and efficient processes for the development of online courses. To test the viability of a learning object approach to online course construction, AU conducted an action research project for Canada's SchoolNet in which four experienced course developers were challenged to develop independent study based, undergraduate courses in which freely available learning objects were extensively used as content (Christiansen \& Anderson, 2004).

The three courses chosen were from different disciplines - Business; English and Nursing. The course development teams were given latitude to develop (or undertake major course revision for) three popular courses that had been offered in print correspondence format. AU course developers were trained in learning object definition and searching of various available learning object repositories. Not surprisingly, the authors encountered variable amounts of resources available, had different concerns related to access and each brought with them unique discipline perspectives and pedagogical contexts. 
The Nursing course was a senior undergraduate 'issues' course and the course developers found a wealth of applicable resources - many from government and professional organisation web sites. They developed the course using a WebCT learning management system and were able to cover the flexible content by linking to and annotating web based objects with relative ease. The extensive list of resources and sites also proved to be good exposure for assignments that required students to develop their own perspectives and do further research on various topical nursing issues.

The second year business communications course used a much tighter expository pedagogy that required students to be exposed to and practise creating and consuming communications tools and techniques in regular use in business contexts. The authors found many available and relevant resources, but had great difficulty in contextualising these disparate resources into a coherent set of content and related activities. In their search of the web, they did, however, find a relevant and relatively inexpensive text book, that provided a full featured set of professionally created learning objects linked to each of the chapters in the text book. They felt that the coherent organisation of the publisher's resources and direct linkage to the text provided a much richer content than could be provided through disparate, freely available objects or that could be developed by the authors (and various other members of a development team) within the time and fiscal restraint demands of the pilot. They eventually developed a simple web site that provided Canadian context to the United States based context of the text and provided a place to add AU course developers' comments, assessment activities criteria and other content relevant to AU learners. They concluded that the challenges of contextualising and creating a well structured course, acceptable to the quality and pedagogical standards within the School of Business, precluded quality course creation using freely available objects at this time.

The third pilot course was Writing for Performance, an upper level English course that focused on writing scripts for stage and television. The developers found a wealth of materials, often from practising playwrights and from other academic institutions. They were able to create a course based upon this freely available content, but were concerned with continuing access and copyright clearance issues. They therefore took considerable time to acquire copyright clearance (usually at no or low cost) for each 'object' used and mirrored the content on an AU web site. This extra step allowed for a sense of security and permanence that free and anonymous use of external objects precludes.

A fourth pilot of a graduate course in a Masters of Distance education program was also developed. In this pilot the learners collaboratively developed portal sites (consisting largely of publicly available objects) on 
emerging technology education issues and were challenged to use these sites to teach their peers. They also submitted the metadata describing and linking to the portals to the major learning object repositories (Anderson \& Wark, 2005).

The results of these four pilots illustrate both the promise and the challenge of creating courses based upon freely available objects. Variations in the requirements of the course, the educational model, the academic discipline, the perspective of the developers and the learning model used, created different opportunities and challenges. It is unlikely that a learning object approach to course creation will develop uniformly across these variables, but there is value to implementations that make extensive use of objects created both by the university and other academic and commercial providers.

\section{The human side of learning object use - testing the repository with end users}

Learning objects and instructional design

Students in the AU Master of Distance Education program adapted educational materials as learning objects and incorporated learning objects into a set of flexible instructional materials. The course materials were revised to include content, activities, online conferencing, and assignments pertaining to the use of learning objects in the adaptation and development of instructional materials. Moisey (2004) concurs, similarly concluding that there are significant human factors associated with the adaptation, use and development of learning objects.

Learning objects and faculty development

A study implementing learning objects into a joint learning technologies and communications course showed that faculty could be rather skeptical regarding the need for learning objects. The eduSource project was useful in creating templates, providing instructors with simple ways of linking online courses to the AU repository. The practical experience gleaned from the project was useful in encouraging greater faculty participation (Baggaley \& Ellerman, 2004).

\section{Learner use of learning objects}

The opportunity to evaluate learner use of learning objects emerged in the convergence of two separate projects; the EduSource initiative and the researchers' ongoing study of affective learning in online learning environments (Cleveland-Innes \& Ally, 2004). In addition to creating a network of interoperable learning object repositories, researchers worked from the premise that learning objects must be designed with the learner in 
focus, and be tagged for easy retrieval, if they are going to add value (Ally, 2004; Krauss \& Ally, 2005). As part of the eduSource project, the retrieval and application of learning objects was evaluated.

This consideration of the use, or application, of learning objects comes as a logical continuation of significant efforts to identify, tag and meta-tag information items in accessible ways. Many possibilities for human growth and development through learning objects exist; this leads to questions about the role of the learner in the learning object enterprise; from development to storage and application. In addition, supporting self directed, continuous learning for individuals is one significant and valuable opportunity in the application of learning objects. Three questions were identified regarding independent learner use: 1) how would learners choose learning objects, 2) what would learners do with learning objects and 3) will they re-use learning objects in order to sustain learning.

In this segment of the eduSource project, students in a training course entitled Meeting Customer Needs in Online Service Environments were directed to supplementary learning material in the form of learning objects housed in the DRR at AU. The learning object description included title, media type and description. Students were asked to freely choose material they thought would be of interest in relation to the course material and objectives.

A total of one hundred and twenty interactions between a learner and a chosen learning object were observed during this phase of the research process. Analysis of learner activity indicates selection of learning objects is based on personal learner needs and expectations for satisfying learning outcomes desired. Learning objects that don't consider the learner's perspective and intrinsic motivation as important driving forces in the selection, use and reuse of learning objects are of little value to the pedagogical process.

It appears that learners used the title of the learning objects to decide whether to view and learn from a learning object. This may be similar to the title for a book or paper which learners use to decide whether to read it or not. Hence, it is important for designers and educators to include a title of the learning object so that learners can search the repository for the appropriate title. Once the title is located, learners will decide whether to access the learning objects based on the title. Also, the type of learning object (print, audio, video, etc) was not an important criterion for deciding whether to select and work through the learning objects. This indicates that learners are more interested in the content of the learning object rather than the format. 


\section{Conclusion}

The AU component of the pan Canadian eduSource project worked toward greater accessibility on all aspects of learning object repository development. Tagging of metadata was created under the name of CanCore, for discoverability. An electronic library interface, the DRR, was a prototype for learner access to learning object repositories. A sophisticated, effective learning object repository application, ADLib, was developed for course materials. Populating the repository involved tagging of metadata in ways most accessible to course designers. Finally, and most importantly, end users from faculty, course designers to learners themselves were engaged in the implementation of learning objects in the teaching and learning enterprise.

The following lessons learned are offered in the form of recommendations for institutions of higher education wishing to develop and use learning object repositories:

1. Consider CanCore as a point of departure. The CanCore metadata work-package addresses structural barriers presented by ad hoc and proprietary solutions. CanCore standards allow for greater reuse and portability of resources, systems and content of many kinds across applications and operating systems for the description of rich, bandwidth intensive multimedia resources.

2. Involve in house faculty and instructional design staff in the repository development process. EduSource engaged course developers to work through and document critical issues including file naming conventions, recommendations for titling objects, and recommendations for CanCore elements. Converting the existing course material to clean $\mathrm{XML}$ text requires a great deal of editing before it can be useful as XML based learning objects. Very little of this process can be automated; AU course developers found this required concerted human intervention and editing.

3. Link learning objects to library holdings to create digital course content support, anytime, anywhere. AU's Digital Reading Room began as an online repository of "reserve" articles and other course materials for use in specific courses. This expanded to a more granular system capable of incorporating different types of learning object resources beyond standard text based articles and books.

4. Provide resources to move instructional design and course development in line with current learning object availability. AU found some success 
in course creation or augmentation using current learning object repositories. This success is dependent upon sound knowledge about learning objects and repositories on the part of instructional designer and course developers, and varies across disciplines.

5. Involve and consider faculty needs and issues at all times. The skepticism of faculty in the face of learning objects can be overcome with detailed examples of ease of use and time saving possibilities. A learning object framework for course delivery provides a useful and convenient platform for them to adopt, and a simple method of linking their online materials as learning objects in a digital repository.

6. Learning object creation, tagging, storing and retrieving must be learner centered. As the ultimate end users, learners also require stability and reliable access to multiple types of learning resources at any time of the day or night, along with the capacity to connect, view and/or manipulate search results. Simple language, clear tagging or cataloguing, explicit learning objectives and opportunities to integrate to other content bits are critical.

AU is committed to creating an interoperable learning object repository and shall continue to experiment with the development of the DRR, AdLib and the pedagogical approaches needed for effective use of learning objects. Future works will involve more experimentation with schema and database implementations for supporting the interoperability of learning objects among different applications and in varied learning environments. Most recently, AU researchers are developing applications for delivering course materials to learners on mobile devices such as PDAs, IPods, and cellular phones.

The experience of AU in implementing an enterprise wide learning object repository has resulted in the development of open implementation standards and tools that can be used by other institutions to speed up their learning object repository development efforts. At AU, this initiative has brought together professionals, academics, and other researchers into a team that has synchronised efforts of different university centres to support the creation of a common, enterprise wide, university repository for learning objects. This has been no mean feat. The eduSource project has provided developers with tools and standards that facilitate interoperability between learning object repositories among different institutions, both nationally and internationally. 


\section{References}

Advanced Distributed Learning (2003). SCORM Overview. [viewed 13 May 2004] http: / / www.adlnet.org/index.cfm?fuseaction=scormabt

Ally, M. (2004). Designing effective learning objects. In R. McGreal (Ed), Online education using learning objects (pp. 87-97). London: Routledge Falmer.

Anderson, T. \& Wark, N (2004). Why do teachers get to learn the most? A case study of a course based on student creation of learning objects. e-Journal of Instructional Science and Technology, 7(2). [verified 28 Aug 2005] http: / / www.usq.edu.au/electpub/ejist/docs/Vol7_no2/FullPapers/WhyDoTeachers.htm

Athabasca University Learning Design Group (2004). Edusource final report. [viewed 3 May 2004] http:/ / edusource.athabascau.ca/files/Edusource_LD_Final_report.doc

Baggaley, J. \& Ellerman, D.E. (2004). Learning objects integration of selected AU courses on educational technology, media research and instructional design. [viewed 3 May 2004] http: / / edusource.athabascau.ca/files/jonbaggaley.doc

Bartz, J. (2002). Great Idea, but how do I do it? A practical example of learning object creation using SGML/XML. Canadian Journal of Learning and Technology, 28, 73-89. http:/ / www.cjlt.ca/ content/vol28.3/bartz.html

Broadvision (2003). Quicksilver: Interleaf for the web. [viewed 3 May 2004] http:/ / www.broadvision.com/attachment/ files/R2071L-f_10-d-bQ3S0Q-w-gm_f_QuickSilver_ds.pdf?BV_SessionID=NNNN1804069359.1083622387NNNN\&BV_Engi neID $=$ ccceadclgfegmgdcefecefedghhdfjk. 0

CANARIE (2004). CANARIE Home Page. [viewed 13 May 2004] http: / / www.canarie.ca/

Christiansen, J. \& Anderson, T. (2004). Feasibility of course development based on learning objects: Research analysis of three case studies. Instructional Technology and Distance Education, March. [viewed 6 April 2004] http: / / www.itdl.org/journal/Mar_04/article02.htm

Cleveland-Innes, M. \& Ally, M. (2004). Affective learning outcomes in workplace training: A test of synchronous vs. asynchronous online learning environments. Canadian Journal of University Continuing Education, 30(1), 15-35.

Cleveland-Innes, M., Ally, M. \& Tin, T. (2004). Experiment with transference of learning objects across disciplines for pedagogical and technical interoperability. [viewed 3 May 2004] http:/ / edusource.athabascau.ca/files/Marti_Mhdt.doc

DCMI (n.d.). Dublin Core Metadata Initiative. http:/ / dublincore.org/ [viewed 13 May 2004]

E-Learning Competency Centre (2004). SingCore. [viewed 13 May 2004] http: / / www.ecc.org.sg/cocoon/ ecc/website/standards/singcore.standards

Friesen, N. (2004). CanCore: EduSource summary. [viewed 1 May 2004] http: / / edusource.athabascau.ca/ files / cancore-normf.doc 
Friesen, N., Hesemeier, S. \& Roberts, T. (2004). CanCore: Guidelines for learning object metadata 2.0. In R. McGreal (Ed), Online education using learning objects. Routledge/Falmer, London.

IEEE (2003). Learning Technologies Standards Committee WG12: Learning object metadata. [viewed 1 May 2004] http:/ / ltsc.ieee.org/wg12/

IMS (2003). IMS Learning Design. [viewed 4 May 2004]

http: / / www.imsglobal.org/learningdesign/index.cfm

ISO (n.d.). JTC 1/SC 36 Information technology for learning, education and training. [viewed 1 May 2004]

http:/ / www.iso.ch/iso/en/stdsdevelopment/techprog/workprog/TechnicalP rogrammeSCDetailPage.TechnicalProgrammeSCDetail?COMMID=4997

Learning Networks of Educational Technology Expertise Centre of the Open University of the Netherlands (n.d.). [viewed 4 May 2004] Learning Network: EML. http:/ / eml.ou.nl/eml-ou-nl.htm

McGreal, R., Anderson, T., Babin, G., Downes, S., Friesen, N., Harrigan, K., Hatala, M., MacLeod, D., Mattson, M., Paquette, G., Richards, G., Roberts, T. \& Schafer, S. (2004). EduSource: Canada's learning object repository network. International Journal of Instructional Technology and Distance Learning, March, 1(3). [viewed 7 April 2004] http:/ / www.itdl.org/Journal/Mar_04/article01.htm

Moisey, S. (2004). Barriers and facilitating factors affecting the use of learning objects in adapting and developing instructional products. [viewed 3 May 2004] http: / / edusource.athabascau.ca / files / susanmoisey-rpt.doc

Petrinjak, A. \& Graham, R. (2004). Creating learning objects from pre-authored course materials: Learning object semantic structure design, technology and related issues. [viewed 3 May 2004]

http: / / edusource.athabascau.ca/ files / Anita_Rodgerr.doc

Contact author: Martha Cleveland-Innes, Associate Professor, Centre for Distance Education, Athabasca University, 1 University Drive, Athabasca AB T9S 3A3, Canada. Web: http:/ / cde.athabascau.ca/ Email: martic@athabascau.ca 